\title{
Pre-season Fitness Level and Injury Rate in Professional Soccer - A Prospective Study
}

\section{(ㄷ)(ㄱ) $($ 우 $\ominus$}

\author{
Authors \\ Eyal Eliakim¹, Ofer Doron', Yoav Meckel', Dan Nemet², Alon Eliakim²
}

\author{
Affiliations \\ 1 Wingate Institute, Zinman College of Physical Education, \\ Netanya, Israel \\ 2 Child Health \& Sports Center, Meir Medical Center, \\ Pediatrics, Sackler School of Medicine, Tel Aviv University \\ Kfar Saba, Israel
}

\section{Key words}

physical conditioning, prevention, football, musculoskeletal injuries

$\begin{array}{ll}\text { received } & 09.02 .2018 \\ \text { revised } & 01.05 .2018 \\ \text { accepted } & 03.05 .2018\end{array}$

Bibliography

DOI https://doi.org/10.1055/a-0631-9346

Sports Medicine International Open 2018; 2: E84-E90

(c) Georg Thieme Verlag KG Stuttgart · New York

ISSN 2367-1890

\section{Correspondence}

Prof. Dan Nemet, MD, MHA.

Child Health \& Sports Center

Meir Medical Center, Meir Medical Center, Pediatrics

59 Tchernichovski

44821, Kfar Saba

Israel

Tel.: + 972/974/72 134, Fax: + 972/974/71303

dnemet@gmail.com

\begin{abstract}
The aim of the present study was to assess prospectively the effect of pre-season fitness on injury rate during the competitive season among professional soccer players. Thirty-one players participated in the study during two consecutive competitive seasons (2015-16 and 2016-17; a squad of 22 players in each season). During the 6 -week pre-season training period ( 8 training sessions and a friendly match every week, 14-18 training hours/week) there was a significant improvement in $\mathrm{VO}_{2}$ max, a significant increase in ideal and total sprint time and no change in vertical jump, flexibility and repeated sprint-test performance decrement. During the two consecutive seasons, 28 injuries were recorded. Ten injuries were classified as mild (missing 3-7 days of practice/match), 8 as moderate (missing $8-28$ days) and 10 as severe (missing $>28$ days). The rate of match injuries was higher (9.4 per 1000 match hours) compared to practice injuries (4.7 per 1000 training hours). Most injuries were overuse injuries (72\%) of the lower limbs (71\%). Most of match injuries occurred during the last 15 min of each half. There were no differences in fitness characteristics in the beginning of pre-season training between injured and noninjured players. However, improvements in $\mathrm{VO}_{2}$ max during the pre-season training period were significantly lower among injured players $(0.9 \pm 5.5 \%)$ compared to non-injured players $(10.4 \pm 6.5 \%, p<0.05)$. Our results emphasize the importance of pre-season training in professional soccer players not only for improvement in fitness but also for injury prevention during the following competitive season.
\end{abstract}

\section{Introduction}

Professional soccer is a complex intermittent contact sport that demands enhanced aerobic and anaerobic skills and involves a relative high risk of injuries [21,22]. In recent years, the game is played faster and became more physical and aggressive demanding intense training and high physical fitness levels [1]. The majority of professional soccer players sustain at least one injury causing layoff from practice or match each season, and the vast majority of injuries are located in the lower extremities [40]. Soccer injuries are known to be associated with the player's age, exercise load (duration, intensity and frequency of practice and particularly matches), professional level, and training standard $[8,14,19,26]$. The sensitivity of elite players to frequent injuries may affect the player's and team's potential to acquire skills and maximize performance [27]. Therefore, medical and coaching staff continuously seek approaches to assist players and teams to compete at the highest level and reach their maximum capabilities while simultaneously avoiding exposure-related injuries [26].

The diagnoses and classifications of soccer injuries differ among studies, making the comparison of results among professional soccer players difficult [33]. Previous studies defined injury and time loss from activity ranging from missing at least one day of activity 
to at least one week $[8,26,32]$, or the next match or training session [32]. Other studies divided soccer-related injuries to practice versus match injuries and to contact compared to overuse injuries [32]. Surprisingly, however, despite the significance of soccer-associated injuries for the team's success, little knowledge exists about injury-related risk factors in elite soccer players [12] and only a few prospective soccer injury studies have been conducted $[19,25]$.

Pre-season soccer training aims to prepare the players mentally and physically for the rest of the season [35]. This period is characterized by the greatest increase in fitness level, but this improvement may not be sufficient to handle the intensity and stress associated with competitive soccer, leading to higher risk of injuries [26]. Therefore, the aim of the present study was to prospectively assess the relationship between pre-season fitness level (i. e., flexibility, speed, explosive power, aerobic capacity) and injury rates among professional soccer players. We hypothesized that lower pre-season fitness components would be associated with a higher injury rate throughout the competitive season.

\section{Materials and Methods}

\section{Participants}

Thirty-one players, members of a single Israeli professional soccer team, participated in the study (height: $179.4 \pm 6.5 \mathrm{~cm}$, weight: $76.1 \pm 7.5 \mathrm{~kg}$, percent body fat: $14.0 \pm 3.0 \%$ ) during two consecutive competitive seasons 2015-16 and 2016-17 (a squad of 22 players in each season). The players were informed of the experimental procedures and requirements before signing an informed consent. All procedures were conducted in accordance with the standards of the Institutional Ethical Committee. The study meets the ethical standards of the journal [20]. Standard, calibrated scales and stadiometers were used to determine body weight and height. Skinfold measurements at four sites (triceps, biceps, subscapular, and supra-iliac) were taken by an experienced technician.

\section{Pre-season training period}

During the 6-week preseason training period, participants trained six days a week, including friendly matches. The physical training programs included mainly aerobic and mixed aerobic-anaerobic type activities with and without the ball as well as speed, strength, stretching and coordination training. In addition, training involved technical drills and team tactics and included a weekly friendly match. Each training session lasted $1.5-2 \mathrm{~h}$ and overall $14-18 \mathrm{~h}$ a week. Training volume and intensity was increased gradually over the weeks in an attempt to avoid overtraining or injuries among the participants. - Table $\mathbf{1}$ describes a typical weekly training program during the six-week pre-season period. Training as well as match volume and intensity were recorded using GPS data (K-sport, Torriana, Italy).

\section{Testing procedures}

Participants performed two similar sets of tests before and after the six-week pre-season training period ( $\vee$ Fig. 1). The first set of tests was conducted on two non-consecutive days during the week prior to the beginning of the training program. The second set of tests was conducted under the same conditions during the week following completion of the training program. Both sets of tests were performed using the same procedures, at the same time of the day, under the same environmental conditions, and by the same examiner. Participants were familiar with the testing procedures because they performed them in previous years. Before each set of tests, participants performed a standard warm-up that included 8 min of jogging, followed by 10 min of stretching exercise and two 30-m submaximal runs (at approximately $80-90 \%$ of maximal sprint speed). A 30-min period separated the different tests on each day. Testing selection was based on the movement type and fitness components applicable for soccer and is consistent with other reports studying fitness of soccer players (e. g.[35]). A high test-retest reliability $(0.80-0.95)$ of the tests used in the present study was previously described [35].

On the first day of each testing set, participants performed the following three tests.

\section{Vertical jump power test}

Jump height was measured by a maximum vertical jump using a countermovement jump (CMJ) technique, with hands on the hips. Participants began in an erect standing position and moved into a semi-squat position before jumping as high as possible. The flight time, measured by an Optojump (Optojump, Microgate, Bolzano, Italy), was used to calculate the change in the height of the body's center of gravity. Three trials were given and the highest jump achieved was recorded.

\section{Sit and reach flexibility testing}

Participants sat with their legs extended on the floor. Feet were placed against a box with a yardstick attached to it. Participants placed their hands one on top of the other, slowly extended them forward, and then held them at the maximum stretch point for $3 \mathrm{~s}$.

> Table 1 A typical schedule of pre-season weekly training.

\begin{tabular}{|c|c|c|c|c|c|c|c|}
\hline Week day & 1 & 2 & 3 & 4 & 5 & 6 & 7 \\
\hline $\begin{array}{l}\text { Morning } \\
(1.5-2 \text { h) }\end{array}$ & $\begin{array}{l}15 \% \mathrm{WU} \\
35 \% \mathrm{TT} \\
35 \% \mathrm{PT} / \mathrm{TT} \\
15 \% \mathrm{CD}\end{array}$ & & $\begin{array}{l}15 \% \mathrm{WU} \\
35 \% \mathrm{TT} \\
35 \% \mathrm{PT} / \mathrm{TT} \\
15 \% \mathrm{CD}\end{array}$ & & $\begin{array}{l}15 \% \mathrm{WU} \\
35 \% \mathrm{TT} \\
35 \% \mathrm{PT} / \mathrm{TT} \\
15 \% \mathrm{CD}\end{array}$ & & Rest \\
\hline $\begin{array}{l}\text { Evening } \\
(1.5-2 \mathrm{~h})\end{array}$ & $\begin{array}{l}15 \% \mathrm{WU} \\
70 \% \mathrm{PT} \\
15 \% \mathrm{CD}\end{array}$ & $\begin{array}{l}15 \% \text { WU } \\
35 \% \text { TT } \\
35 \% \text { PT/TT } \\
15 \% \text { CD }\end{array}$ & $\begin{array}{l}15 \% \mathrm{WU} \\
70 \% \mathrm{PT} \\
15 \% \mathrm{CD}\end{array}$ & $\begin{array}{l}15 \% \text { WU } \\
35 \% \text { TT } \\
35 \% \text { PT/TT } \\
15 \% \text { CD }\end{array}$ & $\begin{array}{l}15 \% \text { WU } \\
70 \% \text { PT } \\
15 \% \text { CD }\end{array}$ & $\mathrm{FM}$ & Rest \\
\hline
\end{tabular}

WU: warm-up; TT: technical training; PT: physical training; CD: cool-down; FM: friendly match. 


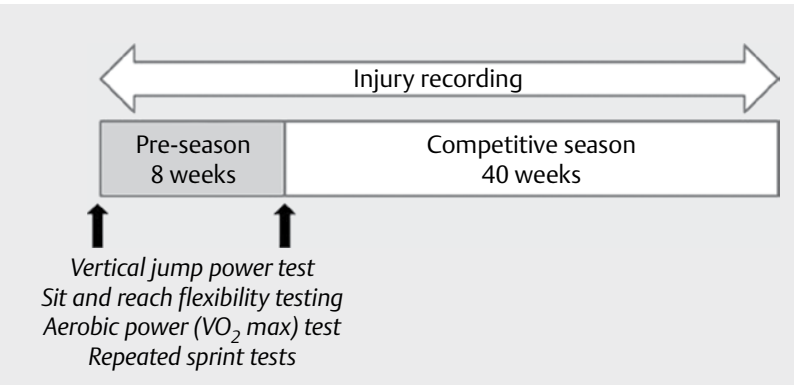

-Fig. 1 Experimental design.

The distance reached on the yardstick was recorded. Three attempts were made and the longest distance on the yardstick was recorded.

\section{Aerobic power $\left(\mathrm{VO}_{2}\right.$ max $)$ test}

An incremental maximal running test on a motor-driven treadmill (Woodway, PPS MED, Weil am Rhein, Germany) was performed to determine maximal aerobic power $\left(\mathrm{VO}_{2} \mathrm{max}\right)$. Although $\mathrm{VO}_{2} \max$ test is not soccer-specific, it is considered a reliable and frequently used measure of aerobic fitness, and therefore was used in the present study. All the participants were experienced in running on a treadmill. Before the beginning of the test, each participant performed a 5 -min familiarization run at $8-8.5 \mathrm{~km} / \mathrm{hr}$. For the actual test, the initial conditions of the treadmill were set at zero grade with a speed of $9 \mathrm{~km} / \mathrm{hr}$. Speed was increased by $1 \mathrm{~km} / \mathrm{hr}$ every min until the fourth stage. From this point on, the grade was increased by $2 \%$ every min while the speed was kept constant until volitional exhaustion occurred. The test was considered maximal when oxygen consumption reached plateau and did not increase with increased exercise intensity. Expired air was collected and analyzed breath-by-breath using an automated on-line system (Sensor Medics, Vmax29, Yorba Linda, CA, USA). The flow and gas concentration sensors of the system were calibrated prior to each test, according to the manufacturer's instructions.

On the second day the participants performed the following test.

\section{Repeated sprint tests}

The RST protocol included a $6 \times 30 \mathrm{~m}$ maximal run starting every $30 \mathrm{~s}$. Each participant performed a $30 \mathrm{~m}$ maximal sprint on a separate day before the performance of the RSTs. The time of the maximal sprint was used as a criterion score for the upcoming RSTs. In the first sprint of each RST, participants were required to achieve at least $95 \%$ of their criterion score. If $95 \%$ of the criterion score was not achieved, the participant was required to restart the RST. Accordingly, the participants were instructed and encouraged by the coaches and investigators to produce maximal effort during each sprint and to avoid pacing themselves. All subjects met the required criterion ( $95 \%$ of maximal speed in the first sprint) and no one had to restart the test.

During the RST, a photoelectric cell timing system (Alge-Timing Electronic, Vienna, Austria) with an accuracy of $0.001 \mathrm{~s}$, linked to a digital chronoscope, was used to record each sprint and each rest interval time. Two sets of timing gates were used, working in opposite directions, to allow the subjects to start the next run from the end point of the preceding sprint, thus eliminating the need to hurry back to a common starting point. A standing start, with the front foot placed $30 \mathrm{~cm}$ behind the timing lights, was used for all sprints. Timing was initiated when the subject broke the light beam. An experimenter was placed at each end of the track to provide verbal encouragement to each subject during each sprint.

The three measures for each RST were the ideal 30-m run time (IS), the total run time (TS) of the 6 sprints, and the performance decrement (PD) during the test. IS was calculated as the fastest 30-m sprint time multiplied by 6 . TS was calculated as the sum of all sprint times. PD was used as an indication of fatigue and was calculated as [(TS/IS) X 100] - 100. The test-retest reliability of running RST is 0.942 for TS and 0.75 for PD $[4,34]$.

\section{Injury recording}

The study covers $720 \mathrm{~h}$ of training for each player in each season (11 months, 6 practices/week, $\sim 2.5 \mathrm{~h} /$ practice). Thus, all together the study covers $\sim 32,000 \mathrm{~h}$ of practice. In addition, during the first season the team played 43 official matches (including regular league, playoffs and cup matches) and during the second season 41 official matches. All together this adds up to 1,386 match hours (84 matches of $1.5 \mathrm{~h} \times 11$ players).

All injuries were recorded by the medical staff of the team. Injuries were classified using the UEFA criteria for injury severity [18]: minimal (misses 1-3 days), mild (misses 4-7 days), moderate (misses 8-28 days), severe (misses over 28 days). Only mild, moderate and severe injuries were recorded. Injuries were subdivided by the site of injury (lower limbs, upper limbs, back and head trauma, etc.) as well as by contact/traumatic versus overuse injuries and practice versus match injuries. Match injuries were subdivided by the timing of injury during the match (first versus second half with each half divided into three 15-min sections).

\section{Statistical analysis}

A two-way repeated-measures ANOVA was used to compare fitness changes during the pre-season training period. Unpaired t-tests were used to compare pre-season fitness level and changes in fitness characteristics during the pre-season training period between injured and non-injured players. A Cohen's d-effect size (ES) was also performed to demonstrate the magnitude of training effect in each group. Data are presented as mean \pm SD. Significance level was set at $\mathrm{p} \leq 0.05$ with Bonferroni correction for multiple comparisons. A Cohen's $d<0.30$ was considered a low effect, $.30-.70$ a moderate effect, and $>0.70$ a strong effect.

\section{Results}

\section{Pre-season training}

GPS assessment of training intensity indicated an average total training distance of $62.49(\mathrm{~m} / \mathrm{min})$, an average metabolic power of $5.68(\mathrm{~W} / \mathrm{Kg})$, a total sprint distance of $1.74(\mathrm{~m} / \mathrm{min})$, and number of sprints 0.21 (sprints/min). Changes in fitness characteristics during the pre-season training period are summarized in $>$ Table 2 . There was a significant improvement in $\mathrm{VO}_{2}$ max and a significant 
increase in ideal sprint time and total sprint time. There were no significant differences in vertical jump, flexibility and RST performance decrement. GPS assessment of match intensity indicated a total match distance of 91.54 ( $\mathrm{m} / \mathrm{min})$, an average metabolic power of $8.48(\mathrm{~W} / \mathrm{Kg})$, a total sprint distance of $5.62(\mathrm{~m} / \mathrm{min})$, and number of sprints 0.53 (sprints/min).

\section{Injury recording}

During the two consecutive seasons 28 , injuries were recorded. Nine players had a single injury and 8 players multiple injuries. Ten injuries were classified as mild (missing 3-7 days of practice/ match), 8 as moderate (missing 8-28 days of practice/match) and 10 as severe (missing $>28$ days of practice/match). The majority of injuries (71\%) were in the lower limbs (6 hamstring, 7 knee, 3 ankle, 2 gastrocnemius, 2 quadriceps). Eleven injuries occurred in defenders and 10 in midfield players. Eight injuries were traumatic/contact injuries (28\%) and 20 were overuse injuries ( $72 \%)$. None of the injuries were fractures. Thirteen injuries occurred during matches (46\%) and 15 during practice (54\%). Most match injuries occurred during the final $15 \mathrm{~min}$ of the first half or second half (8/13).

\section{Relationship between pre-season fitness and injuries}

Differences in pre-season fitness characteristics between injured and non-injured players, as well as changes in fitness characteristics during the pre-season training period in the injured and noninjured players are summarized in $>$ Table 3 and $>$ Fig. 2. Relative improvements in $\mathrm{VO}_{2}$ max were significantly lower in the injured players compared to the non-injured players.

- Table 2 Changes in fitness characteristics following the pre-season training $\left({ }^{*} p<0.05\right)$.

\begin{tabular}{|l|c|c|}
\hline & \multicolumn{2}{|c|}{ Pre-season training } \\
\hline Fitness characteristics & Pre & Post \\
\hline $\mathrm{VO}_{2}$ max $(\mathrm{ml} / \mathrm{min} / \mathrm{kg})$ & $53.8 \pm 3.0$ & $56.6 \pm 2.9^{*}$ \\
\hline Vertical jump (cm) & $38.2 \pm 2.6$ & $37.5 \pm 2.5$ \\
\hline Flexibility (cm) & $48.8 \pm 4.3$ & $49.2 \pm 3.6$ \\
\hline Ideal sprint time (sec) & $22.98 \pm 1.01$ & $23.79 \pm 0.58^{*}$ \\
\hline Total sprint time (sec) & $23.61 \pm 0.99$ & $24.30 \pm 0.62^{*}$ \\
\hline $\begin{array}{l}\text { RST Performance } \\
\text { decrement (\%) }\end{array}$ & $2.8 \pm 0.9$ & $2.2 \pm 0.6$ \\
\hline
\end{tabular}

\section{Discussion}

Soccer injuries and particularly injuries of key players may reduce team performance. However, the relative effect of injuries on team performance is not easy to determine because injured players are substituted by either bench players from the same team or by new players from other clubs. This suggests that soccer injuries clearly involve a financial burden and that teams with greater resources may cope better with soccer injuries [2]. In the present study, we determined the effect of pre-season fitness on injury rate during two consecutive competitive seasons among professional soccer players. The rate of match injuries was higher compared to practice injuries, with most match injuries occurring during the final stages of each half. Most injuries were overuse injuries of the lower limbs. The main finding of the study was that although there were no differences in initial fitness characteristics (in the beginning of pre-season training) between injured and non-injured players, improvements in $\mathrm{VO}_{2}$ max during the pre-season training period were significantly lower among injured players compared to non-injured players. Because, as mentioned earlier, factors like the player's age, fitness level, training load and professional level may all affect a soccer player's injury risk, substantiating a direct causality between pre-season $\mathrm{VO}_{2}$ max changes and injury risk is challenging. However, the results may emphasize the importance of the pre-season period training in professional soccer players not only for improve-

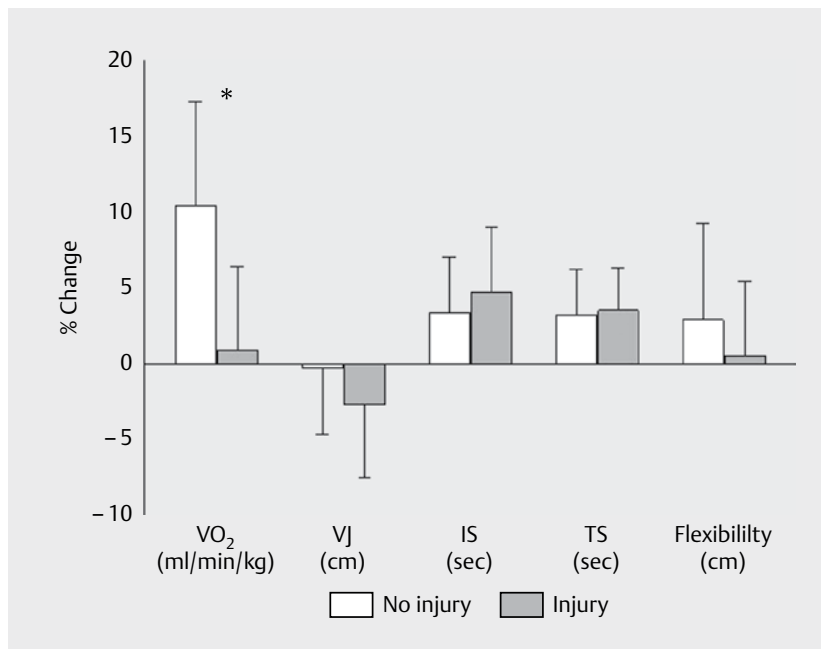

- Fig. 2 Percent change in fitness characteristics following preseason training among injured and non-injured players (VJ: vertical jump; IS: ideal sprint time; TS: total sprint time; $\left.{ }^{*} \mathrm{p}<0.05\right)$.

- Table 3 Changes in fitness characteristics among injured and non-injured players ( ${ }^{*} \mathrm{p}<0.05$ for between group differences).

\begin{tabular}{|l|c|c|c|c|c|c|}
\hline \multirow{2}{*}{ Fitness characteristics } & \multicolumn{3}{|c|}{ Injured $(\mathbf{n}=\mathbf{1 7})$} & \multicolumn{3}{c|}{ Non-injured (n=14) } \\
\cline { 2 - 7 } & Pre & Post & $\begin{array}{c}\text { Effect } \\
\text { size }\end{array}$ & Pre & Post & Effect size \\
\hline $\mathrm{VO}_{2} \mathrm{max}(\mathrm{ml} / \mathrm{min} / \mathrm{kg})$ & $58.1 \pm 2.3$ & $58.3 \pm 3.4$ & 0.16 & $54.7 \pm 3.2$ & $60.2 \pm 3.3^{*}$ & 0.99 \\
\hline Vertical jump (cm) & $39.4 \pm 2.6$ & $38.5 \pm 2.8$ & 0.25 & $36.8 \pm 3.9$ & $36.5 \pm 3.5$ & 0.12 \\
\hline Flexibility (cm) & $51.8 \pm 4.9$ & $51.8 \pm 4.2$ & 0.10 & $45.6 \pm 5.7$ & $46.5 \pm 4.7$ & 0.04 \\
\hline Ideal sprint time (sec) & $23.0 \pm 1.5$ & $24.0 \pm 0.8$ & 0.63 & $22.9 \pm 1.4$ & $23.6 \pm 0.7$ & 0.44 \\
\hline Total sprint time (sec) & $23.7 \pm 1.2$ & $24.5 \pm 0.8$ & 0.51 & $23.5 \pm 1.5$ & $24.1 \pm 0.8$ & 0.32 \\
\hline RST Performance decrement (\%) & $3.2 \pm 1.5$ & $2.2 \pm 0.9$ & 0.51 & $2.4 \pm 0.8$ & $2.2 \pm 0.6$ & 0.33 \\
\hline
\end{tabular}


ment in fitness characteristics but also for injury prevention during the following competitive season.

Pre-season training in the present study was associated with a significant improvement in $\mathrm{VO}_{2}$ max. This is consistent with previous reports indicating that pre-season training and particularly time spent at high intensity was associated with positive effects on aerobic fitness, whereas exposure time in terms of accumulated training, match and combined training and match time showed conflicting results [24]. Because the pre-season training emphasized mainly aerobic features and was associated with high training volume combined with high-intensity interval training, it is not surprising that other fitness characteristics like the vertical jump did not improve, and there was even a small but significant increase in ideal and total sprint time. This could also be explained by a fatigue effect because we performed the post-training tests immediately at the end of training without allowing for a sufficient recovery time for the players [23, 30]. Studies examining anaerobic fitness changes during the pre-season training period demonstrated inconsistent results. Whereas some studies reported significant improvement in speed, power and agility performance $[10,28]$, others failed to find such improvement $[29,36]$. The inconsistency in these studies may result from differences in the training programs and the population studied (professional compared to semiprofessional adult or youth players).

The total match injury incidence in the present study was 9.4 per 1,000 match hours and the total practice injury incidence was 4.7 per 1,000 training hours. This is consistent with previous reports indicating that the risk for injury was higher during matches than during training [38] and that more severe injuries occur during matches [31]. It was shown that the injury rate during competition ranged from 8.7 injuries to 65.9 injuries per $1,000 \mathrm{~h}$ of exposure, and injury incidence during practice ranged from 1.4 injuries to 5.8 injuries per $1,000 \mathrm{~h}$ of exposure. Several potential causes may explain the higher rate of match injuries, including higher game intensity, greater aggressiveness compared to training, and willingness of the players to take more risks during matches. Consistent with that, GPS data from the present study indicates that the total distance covered by the players is about $50 \%$ higher during matches compared to average training, and that the number of sprints doubled, and the total sprint distance tripled during matches.

As previously described [27,39], lower limbs and particularly the upper leg (mainly the hamstring) was the most frequently reported injury, followed by the knee and the ankle. The most common injury types were strains and sprains [21], and there were no fractures. In contrast to previous reports demonstrating that overuse injuries accounted for $27 \%$ to $33 \%$ of the injury incidence [32], $72 \%$ of injuries in the present study were overuse injuries. This is important because different risk factors and mechanisms lead to traumatic and overuse injuries [37]. The main causes of overuse injuries are repetitive stress without sufficient recovery time [5] suggesting that monitoring variations of practice and match intensities as well as implementing appropriate recovery is essential in soccer players. Another possible cause for the higher rate of overuse injuries was the relatively higher incidence of re-injuries in the present study ( $47 \%$ of the players) because the cause of re-injuries is mainly overuse ( $9-30 \%$ of all injuries were reported as re-injuries $[7,19,39]$, and $63 \%$ of those were overuse injuries [39]). On aver- age, a professional soccer player experiences one activity-limiting injury per season [26]. Previously injured soccer players had a 4 to 7 times greater risk for subsequent injury [3]. Thus, injury incidence probability rises throughout a player's career, possibly leading to an increased injury rate in professional players [32]. Moreover, occurrence of minimal and mild injuries should not be ignored because they may predispose soccer players to re-injury, new injuries, and possibly more severe injuries [21]. Inadequate rehabilitation from prior injury, a high level of team pressure for premature return to play, or a player's eagerness for early return to play prior to complete recovery (and inaccurate reporting to the team coaching and medical staff) are possible risk factors for re-injuries among soccer players that may lead to longer absences than with new injuries. This indicates the need for controlled rehabilitation processes using functional objective measures before return to participation in team practice and matches as well as improvement in coaches and players education aiming to reduce the risk of re-injury in professional soccer $[16,17]$.

The injury incidence during soccer matches is influenced by the playing position and occurs mainly among midfielders followed by defenders [7, 9]. In the present study the majority of injuries occurred also in midfield and defensive players but was equally distributed. In addition, and consistent with our results, injury incidence increases toward the end of each half of the match probably due to increased fatigue as the game progresses [13]. Moreover, players tend not to stop playing immediately after sustaining injuries during the match, and sometimes try to continue and play until the half time break in order to receive longer medical treatment and come back to play. This may lead to worsening of their initial injury severity [13].

A demanding match schedule and reduced recovery time between matches also leads to an increase in injury incidence [11]. A recovery time of 72 to $96 \mathrm{~h}$ between two matches was sufficient to maintain physical performance level but was not enough to maintain a low injury rate. In addition, playing in too many matches, which may happen in successful teams playing in the regular league and different cups, nationally and internationally, or in players who also play for their national teams can lead to overtraining, physical and mental burnout, and reduced motivation and, as a result, to a greater risk of injury [15]. However, a demanding, intense match schedule did not play a role in the incidence of injuries in the present study.

Another possible risk factor for injuries is a possible imbalance between the training intensity perceived by the coaching team and by the players. It was previously shown that youth players (under 19) reported a higher intensity and training load than the coaching staff's intention [6]. This issue is of importance in team sports due to the discrepancy among players fitness level. As a result, similar training sessions may lead to permanent overload in some players and expose them to higher injury risk, emphasizing the need for better supervised and individualized inspection of the team training program. Possible differences in training perception between the players and the coaching team were not analyzed in the present study. Finally, inability of players to receive proper rest between two competitive seasons may also increase the injury risk such as may occur in players participating in their continent championships, World Cup, Champions league, European league or other 
tournaments [15]. This, however, was not the case in the present study because players received proper active rest prior to the first season and between the two seasons, and there was no difference in the injury rate between the two seasons.

The effect of pre-season fitness on injury rates.

To the best of our knowledge, this is the first report on the effect of pre-season fitness level and the rate of soccer injuries in the subsequent competitive season. Le Gall et al. [27] demonstrated that injuries peaked during the first few months of the soccer season in youth soccer players and suggested that pre-season conditioning of professional soccer players was not associated with a sufficient improvement in fitness to handle the intensity and stress associated with playing competitive soccer. In the present study, injury incidence was not higher in specific parts of the season. The fitness characteristics that we evaluated in the present study were power (using vertical jump test), flexibility (using the sit and reach test), speed (using repeated sprint test) and aerobic capacity (using the $\mathrm{VO}_{2}$ max test). In contrast to our hypothesis, we did not find differences in fitness characteristics at the beginning of pre-season training between injured and non-injured players. However, the improvement in $\mathrm{VO}_{2}$ max during the pre-season training period was significantly lower among injured compared to non-injured players. Changes in other fitness characteristics (speed, power, flexibility) were not associated with higher injury rate. These results emphasize the importance of the pre-season training period not only for the necessary fitness enhancement needed to compete at a high level during the demanding soccer season but also for injury prevention during the following competitive season among professional soccer players. It is possible that only the changes in $\mathrm{VO}_{2}$ max (and not other measured fitness components) were associated with injury rates because pre-season soccer training focuses on and is known to improve mainly aerobic fitness characteristics [24], whereas the effect of pre-season training on speed, power and agility performance has demonstrated conflicting results [10,29].

However, one limitation of the present study is that we followed a single competitive soccer team (a squad of 22 players in each season, all together 31 players). Including additional teams (different training methods, loads, etc.) could reveal that other fitness characteristics (like speed, explosive power and flexibility) may also affect injury rate.

In summary, the present prospective study demonstrated that an inappropriate pre-season training period as indicated by lower improvement in aerobic fitness was associated with a higher incidence of players' injuries throughout the competitive soccer season. This suggests a possible role for high-quality pre-season soccer training not only for shaping physical fitness, but also (among other factors) for injury prevention.

\section{Conflicts of Interest}

The authors declare that they have no conflict of interest.

\section{References}

[1] Andersen TE, Tenga A, Engebretsen L, Bahr R. Video analysis of injuries and incidents in Norwegian professional football. Br J Sports Med 2004; 38: 626-631

[2] Arnason A, Sigurdsson SB, Gudmundsson A, Holme I, Engebretsen L, Bahr R. Physical fitness, injuries, and team performance in soccer. Med Sci Sports Exerc 2004; 36: 278-285

[3] Arnason A, Sigurdsson SB, Gudmundsson A, Holme I, Engebretsen L, Bahr R. Risk factors for injuries in football. Am J Sports Med 2004; 32: 5S-16S

[4] Bishop D, Spencer M, Duffield R, Lawrence S. The validity of a repeated sprint ability test. J Sci Med Sport 2001; 4: 19-29

[5] Brenner JS. American Academy of Pediatrics Council on Sports Medicine and Fitness. Overuse injuries, overtraining, and burnout in child and adolescent athletes. Pediatrics 2007; 119: 1242-1245

[6] Brink MS, Frencken WG, Jordet G, Lemmink KA. Coaches' and players' perceptions of training dose: Not a perfect match. Int J Sports Physiol Perform 2014; 9: 497-502

[7] Cloke D, Moore O, Shah T, Rushton S, Shirley MD, Deehan DJ. Thigh muscle injuries in youth soccer: Predictors of recovery. Am J Sports Med 2012; 40: 433-439

[8] Dauty M, Collon S. Incidence of injuries in French professional soccer players. Int J Sports Med 2011; 32: 965-969

[9] Deehan D], Bell K, McCaskie AW. Adolescent musculoskeletal injuries in a football academy. J Bone Joint Surg $\mathrm{Br}$ 2007; 89: 5-8

[10] Dragijsky M, Maly T, Zahalka F, Kunzmann E, Hank M. Seasonal variation of agility, speed and endurance performance in young elite soccer players. Sports 2017; 5: 12

[11] Dupont G, Nedelec M, McCall A, McCormack D, Berthoin S, Wisloff U. Effect of 2 soccer matches in a week on physical performance and injury rate. Am J Sports Med 2010; 38: 1752-1758

[12] Dvorak J, Junge A, Chomiak J, Graf-Baumann T, Peterson L, Rosch D, Hodgson R. Risk factor analysis for injuries in football players. Possibilities for a prevention program. Am J Sports Med 2000; 28: S69-S74

[13] Eirale C, Farooq A, Smiley FA, Tol JL, Chalabi H. Epidemiology of football injuries in Asia: A prospective study in Qatar. J Sci Med Sport 2013; 16: 113-117

[14] Ekstrand J, Hagglund M, Walden M. Epidemiology of muscle injuries in professional football (soccer). Am J Sports Med 2011; 39: 1226-1232

[15] Ekstrand J, Walden M, Hagglund M. A congested football calendar and the wellbeing of players: Correlation between match exposure of European footballers before the World Cup 2002 and their injuries and performances during that World Cup. Br J Sports Med 2004; 38 : 493-497

[16] Ergun M, Denerel HN, Binnet MS, Ertat KA. Injuries in elite youth football players: A prospective three-year study. Acta Orthop Traumatol Turc 2013; 47: 339-346

[17] Fuller CW, Bahr R, Dick RW, Meeuwisse WH. A framework for recording recurrences, reinjuries, and exacerbations in injury surveillance. Clin J Sport Med 2007; 17: 197-200

[18] Hagglund M, Walden M, Bahr R, Ekstrand J. Methods for epidemiological study of injuries to professional football players: Developing the UEFA model. Br J Sports Med 2005; 39: 340-346

[19] Hagglund M, Walden M, Ekstrand J. Injury incidence and distribution in elite football - a prospective study of the Danish and the Swedish top divisions. Scand J Med Sci Sports 2005; 15: 21-28

[20] Harriss D], Macsween A, Atkinson G. Ethical standards in sport and exercise science research: 2018 update. Int J Sports Med 2017; 38: $1126-1131$ 
[21] Hawkins RD, Fuller CW. A prospective epidemiological study of injuries in four English professional football clubs. Br J Sports Med 1999; 33: 196-203

[22] Hawkins RD, Hulse MA, Wilkinson C, Hodson A, Gibson M. The association football medical research programme: An audit of injuries in professional football. Br J Sports Med 2001; 35: 43-47

[23] Hill-Haas SV, Coutts AJ, Rowsell G], Dawson BT. Generic versus small-sided game training in soccer. Int J Sports Med 2009; 30: 636-642

[24] Jaspers A, Brink MS, Probst SG, Frencken WG, Helsen WF. Relationships between training load indicators and training outcomes in professional soccer. Sports Med 2017; 47: 533-544

[25] Johnson A, Doherty PJ, Freemont A. Investigation of growth, development, and factors associated with injury in elite schoolboy footballers: Prospective study. BMJ 2009; 338: b490

[26] Junge A, Dvorak J. Soccer injuries: A review on incidence and prevention. Sports Med 2004; 34: 929-938

[27] Le Gall F, Carling C, Reilly T, Vandewalle H, Church J, Rochcongar P. Incidence of injuries in elite French youth soccer players: A 10 -season study. Am J Sports Med 2006; 34: 928-938

[28] Magal M, Smith RT, Dyer J], Hoffman JR. Seasonal variation in physical performance-related variables in male NCAA Division III soccer players. J Strength Cond Res 2009; 23: 2555-2559

[29] Meckel Y, Gefen Y, Nemet D, Eliakim A. Influence of short vs. long repetition sprint training on selected fitness components in young soccer players. J Strength Cond Res 2012; 26: 1845-1851

[30] Meckel Y, Harel U, Michaely Y, Eliakim A. Effects of a very short-term preseason training procedure on the fitness of soccer players. J Sports Med Phys Fitness 2014; 54: 432-440
[31] Morgan BE, Oberlander MA. An examination of injuries in major league soccer. The inaugural season. Am J Sports Med 2001; 29: 426-430

[32] Pfirrmann D, Herbst M, Ingelfinger P, Simon P, Tug S. Analysis of injury incidences in male professional adult and elite youth soccer players: A systematic review. J Athl Train 2016; 51: 410-424

[33] Price RJ, Hawkins RD, Hulse MA, Hodson A. The Football Association medical research programme: An audit of injuries in academy youth football. Br J Sports Med 2004; 38: 466-471

[34] Spencer M, Fitzsimons M, Dawson B, Bishop D, Goodman C. Reliability of a repeated-sprint test for field-hockey. J Sci Med Sport 2006; 9: 181-184

[35] Stolen T, Chamari K, Castagna C, Wisloff U. Physiology of soccer: An update. Sports Med 2005; 35: 501-536

[36] Taylor J, Portas MD, Wright MD, Hurst C, Weston M. Within-season variation of fitness in elite youth female soccer players. J Athl Enhanc 2012; 1:

[37] van Mechelen W, Hlobil H, Kemper HC. Incidence, severity, aetiology and prevention of sports injuries. A review of concepts. Sports Med 1992; 14: 82-99

[38] Walden M, Hagglund M, Ekstrand J. Injuries in Swedish elite football - a prospective study on injury definitions, risk for injury and injury pattern during 2001. Scand J Med Sci Sports 2005; 15: 118-125

[39] Walden M, Hagglund M, Ekstrand J. UEFA Champions League study: A prospective study of injuries in professional football during the 2001-2002 season. Br J Sports Med 2005; 39: 542-546

[40] Wong P, Hong Y. Soccer injury in the lower extremities. Br J Sports Med 2005; 39: 473-482 